\title{
Energy harvesting of two cantilever beams structure: Interfacing circuit discussion
}

\author{
Yu-Yin Chen ${ }^{\mathrm{a}}$, Dejan Vasic ${ }^{\mathrm{a}, \mathrm{b}}$ \\ ${ }^{a}$ SATIE, UNIVERSud, ENS Cachan, 94235 Cachan, France \\ ${ }^{b}$ Université de Cergy-Pontoise, Neuville/Oise, 95031 Cergy Pontoise, Cedex, France
}

\begin{abstract}
Today research on supplying of low power consumption device is highly focused on piezoelectric energy harvesting from ambient vibration. The most popular structure is a cantilever beam with piezoelectric patch to convert mechanical energy into electric energy. In the past researches, the theoretical analysis and interfacing circuit design of single cantilever beam structure is highly developed. In this study, the electrical interfacing circuit of two (or more) piezoelectric generators connected to only one load is proposed and discussed. The nonlinear synchronized switching technique SSHI (Synchronized Switching Harvesting in Inductor) is examined to increase the power efficiency effectively of each piezoelectric generator. In the multiple cantilever beam or flag structure application, the structure may be composed of many piezoelectric patches and the interfacing circuit becomes more complicated and important. From the theoretical analysis and the governing equation, the equivalent circuit of two cantilever beam will be proposed and simulated with the optimized synchronous electric charge extraction (OSECE) nonlinear technique to optimize the interfacing circuit and increase the power efficiency by using the Matlab and PSIM software. The experiments will also show the good agreement with the theoretical analysis. The interfacing circuit design concept in the two cantilever beams structure can be further used in the multi-piezoelectric patches energy harvesting system such as piezoelectric flag to optimize the circuit and increase the power efficiency.
\end{abstract}

Keywords: Energy harvesting, piezoelectric, interfacing circuit, piezoelectric flag.

\section{INTRODUCTION}

Based on the highly advanced in integrated circuits technology, energy harvesting from the ambient to provide the low power consumption device and microscale electronics become a practical and interesting topic during past decades. As piezoelectric materials are high power density, reliability and robustness, it becomes one of the most popular materials to be used in energy harvesting to transfer the vibration energy to electrical energy. Many researchers made efforts in developing energy harvesting devices from vibrations using cantilever beam based energy harvesters due to its simplicity and high efficient on generating large strain and power output [1-9]. Tang et al. [10] and Khaligh et al. [11] demonstrated the state of the art vibration piezoelectric energy harvesting setup based on simple cantilever beam design. Typical cantilever beam structure is shown in Figure 1. Instead of using the conventional one-layer piezoelectric cantilever beam type energy harvester, Roundy and Wriht in 2004 [12] developed, validated, and optimized the basic analytical model for a two-layers bending element type (bimorph type) piezoelectric vibration based energy harvester. They also designed a power generation circuit to demonstrate the application worked with wireless sensor networks.

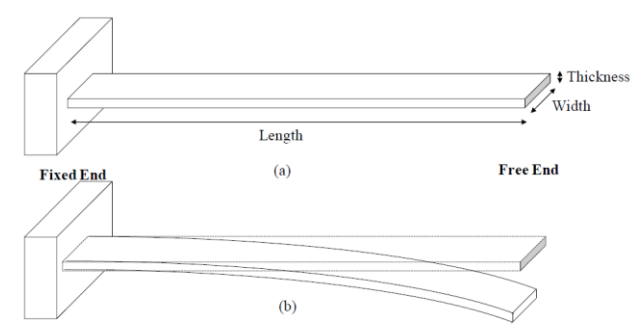

Figure 1. (a) Typical cantilever beam (b) Cantilever beam deflection at first mode 
The piezoelectric elements convert the vibration energy of the host structure into electrical energy, and then the generated electrical energy is stored in a capacitor or a battery. Since the piezoelectric element has larger intrinsic capacitance, an impedance matching circuit is required to maximize the generated power. Although the matching electric circuit can be optimized by a passive network [1], it cannot be adaptive to the variations of environmental vibrations. The exciting frequency of environmental vibrations cannot be always at one constant value and fits to the natural frequency of the energy harvesting device. To overcome this drawback, a switching circuit [13] was proposed and popularly used in recent years. In the switching circuits, the switches are operated synchronously with the vibration of the host structure in order to optimize the power flow.

Several synchronized switching circuit topologies and corresponding switching laws were proposed. The most efficient switching techniques can be classified into two groups according to the placement between the full-wave bridge rectifier and the switches. The first group of the switching circuits places the switches before the full-wave bride rectifier, such as parallel-SSHI (Synchronized Switching Harvesting on an Inductor) as Figure 2(a) and series-SSHI [1, 2] as Figure 2(b); the second group places the switches after the full-wave bridge rectifier, such as SECE technique as Figure 2(c) [1]. Besides by using the full-bride to rectifier the piezoelectric voltage and in order to increase the efficiency, Wu et al. [14] propose the Optimized synchronous electric charge extraction (OSECE) technique as Figure 4(d). In this technique, a transformer and three diodes are instead of the inductor and full-bridge to rectifier the piezoelectric voltage and isolate the primary and secondary side. In these techniques, the switching circuit only turns "ON" at the extreme value of the displacement or at the zero crossing of velocity to shift the phase of the voltage across the piezoelectric element. These techniques are used because the piezoelectric-generator is weakly coupled to the host structure, i.e. only a small amount of mechanical energy is taken from the structure and converted in electricity. The electrical behavior of the piezoelectricgenerator with the SSHI circuit is equivalent to an operation under strong coupling conditions by increasing the output voltage [15].

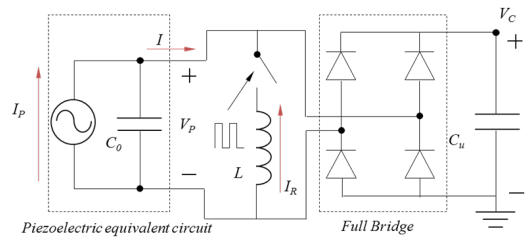

(a)

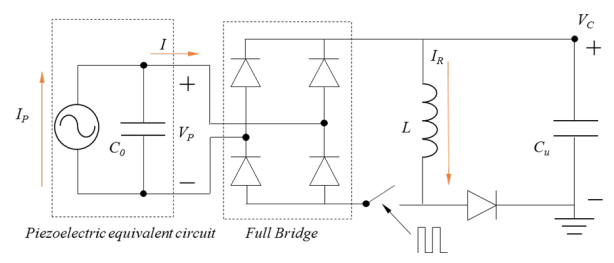

(c)

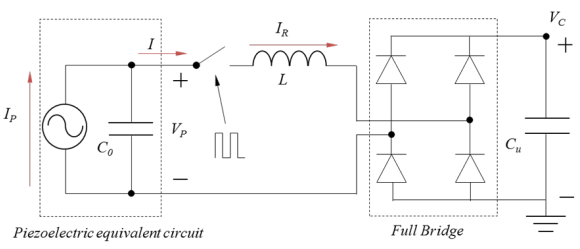

(b)

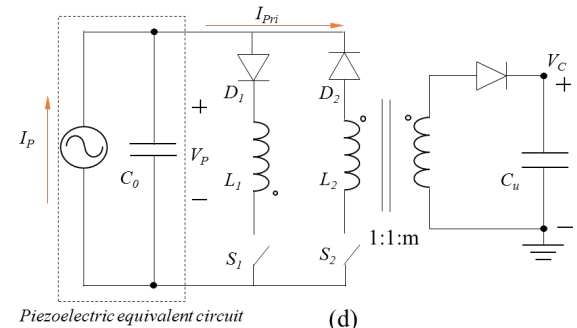

(d)

Figure 2 (a) Parallel-SSHI interface circuit (b) Series-SSHI interface circuit (c) Synchronized charge extraction interface circuit (SECE). (d) Optimized synchronous electric charge extraction (OSECE).

In order to make the synchronized switching technique in the real application, the self-powered synchronized switching technique is proposed by using the velocity control [7]. This self-powered technique can be further used in the structural damping application [16] and bicycle energy harvesting applications [17]. Broadening the band-width of the resonance is also an important topic to increase the power output and the bistable broadband technique with the synchronized switching technique is proposed [18]. Except simple single cantilever beam structure design, Hao Wu et al. presented a novel two-degrees-of-freedom piezoelectric energy harvester as Figure 3 shown [19]. The conventional piezoelectric energy harvester consists of one cantilever beam and the proof mass is placed on the free end. In the novel 2 beams structural design, the two low resonant frequencies can be close to each other and the bandwidth of the energy harvesting system can be broaden by tuning the proof masses. 
Considering multi-piezoelectric patches in the energy harvesting system and in order to harvest the energy to single load, a simple electrical interfacing circuit is proposed by using the OSECE technique in this study. The simplest multipiezoelectric patches system is 2 piezoelectric patch as Figure 4 shown. The 2 piezoelectric patches are placed in the system to improve the power output and the two cantilever beams energy harvester consists of two piezoelectric patches can be shown as Figure 4. In this two beams system, there are two piezoelectric patches harvest the energy at the same time and through the nonlinear interfacing circuit which is composed of the OSECE technique to supply a single load. The conventional SSHI technique is designed to be used for single piezoelectric patch to a single load and in the multi piezoelectric patches system as there are one single load, the interfacing circuit must be redesigned to optimal the elements and power efficiency. The multi-piezoelectric patches combined technique proposed in this study can be further used in the piezoelectric flag system as Figure 5 shown. O. Doaré, and S. Michelin propose the energy harvesting fluttering flexible plates composed of many piezoelectric patches [20,21]. The flow energy is transferred into electrical energy through these piezoelectric patches on the fluttering flexible plates. In this kind of multi-piezoelectric patches applications, combining the electrical energy to a single load become important.

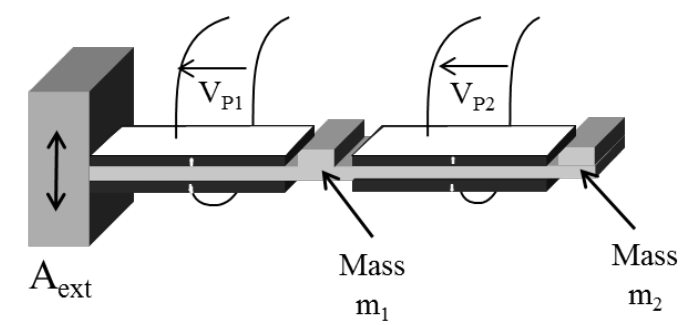

Figure 3. Cantilever beam with magnifier energy harvester with two piezoelectric patches

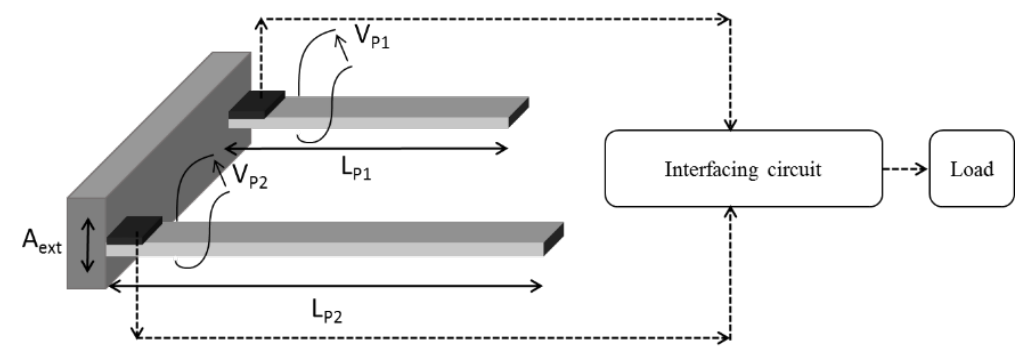

Figure 4. Two cantilever beams piezoelectric energy harvester.

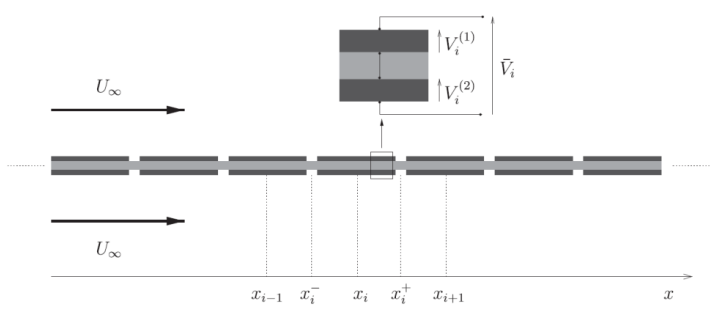

Figure 5. Schematic view of a plate in a homogeneous axial flow, equipped with small length piezoelectric patches on both sides. [21, 22] 


\section{EQUIVALENT MODEL AND THEORETICAL ANALYSIS}

The single degree of freedom modal of classical cantilever piezoelectric energy harvesting driven at the resonance can be represented as Figure 6 shown. Figure 6(a) shows the equivalent mechanical model and Figure 6(b) shows the equivalent circuit model. $M, K^{E}$, and $D$ represent the mass, spring and damper of the system. According to the equivalent circuit model and governing equations can be given by equation (1) and (2).

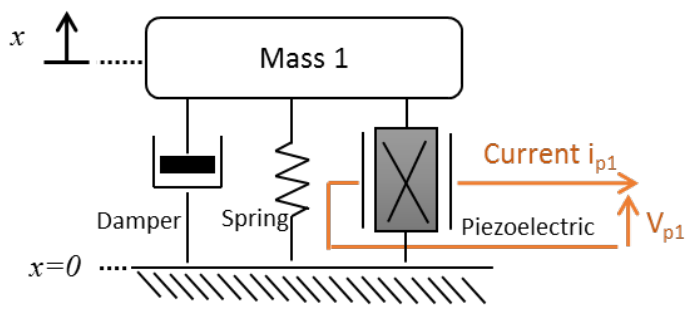

(a)

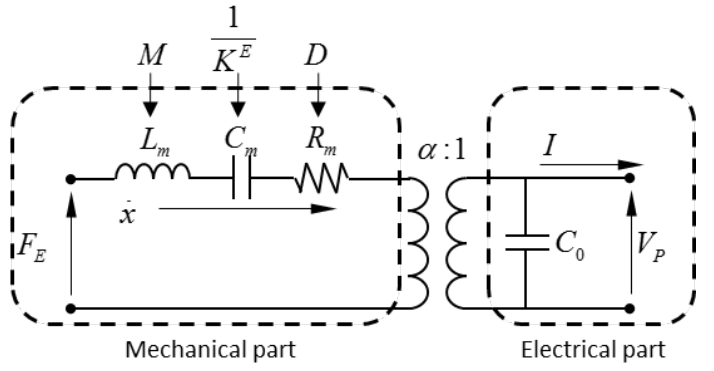

(b)

Figure 6. (a) Equivalent mechanical model and (b) Equivalent circuit model of piezoelectric patch.

$$
\begin{gathered}
m \ddot{x}+D \dot{x}+K^{\mathrm{E}} x=F_{E}-\alpha V_{P} \\
I=\alpha \dot{x}-C_{0} \dot{V}_{P}
\end{gathered}
$$

Where $F_{E}, V_{P}, I$ and $x$ refer to external driving force, piezoelectric terminal voltage, piezoelectric output current and the displacement of the system. $\alpha$ and $C_{0}$ are the piezoelectric force-voltage coefficient and the clamped capacitor of the piezoelectric patch. According to the equivalent circuit model of piezoelectric patch and two beams system in the Figure 4, the two beams combined piezoelectric energy harvesting system charge to single load system by improved OSECE technique can be represented as Figure 7 shown. In order to combine energy from two beams, the improved OSECE technique is proposed in this study and there is a 4 primary windings and 1 secondary winding transformer. For experimental reason, the improved OSECE technique can be simplified as Figure 8 shown and these two circuits are exactly the same. The two piezoelectric patches connected to the two OSECE circuits separately and the OSECE circuit is composed of a 3 windings transformer (two windings in primary and one in secondary), two diodes and two switches. As the conventional synchronized switching technique, the two switches are closed when the tip displacement reaches to the maxima value. The transformer in the OSECE is instead of the inductor in the synchronized switching technique to resonate with the clamped capacitor of the piezoelectric patch to withdraw the electrical energy from the piezoelectric patch and increase the output power. The waveforms are shown in Figure 9 and output power of OSECE technique is given in equation (3) [14]. 


$$
\left\{\begin{array}{l}
P_{\text {OSECE }}=\frac{2 \alpha^{2} \omega}{\pi C_{0}} \frac{\sin ^{2}\left(\omega_{1} t_{m}\right) e^{-\frac{\omega_{1} t_{m}}{Q_{l}}}}{\left[1+\cos \left(\omega_{1} t_{m}\right) e^{-\frac{\omega_{1} t_{m}}{Q_{l}}}\right.} x_{M}^{2} \\
\omega_{1} t_{m}=\operatorname{artan}\left(-m \sqrt{\frac{2 \pi}{R_{L} C_{0} \omega}}\right)+\pi
\end{array}\right.
$$

Where $\omega_{\mathrm{I}}=\frac{1}{\sqrt{L_{I} C_{0}}}$ and $Q_{I}=\frac{1}{r_{I}} \sqrt{\frac{L_{I}}{C_{0}}}$ are the natural angular frequency and the quality factor for the LC resonance. $m$ is the turn's ration in the OSECE as shown in Figure 2(d). $L_{I}, C_{0}$ and $r_{I}$ refer to inductance of the transformer in OSECE, clamped capacitance of piezoelectric patch and resistance of the LC resonance.

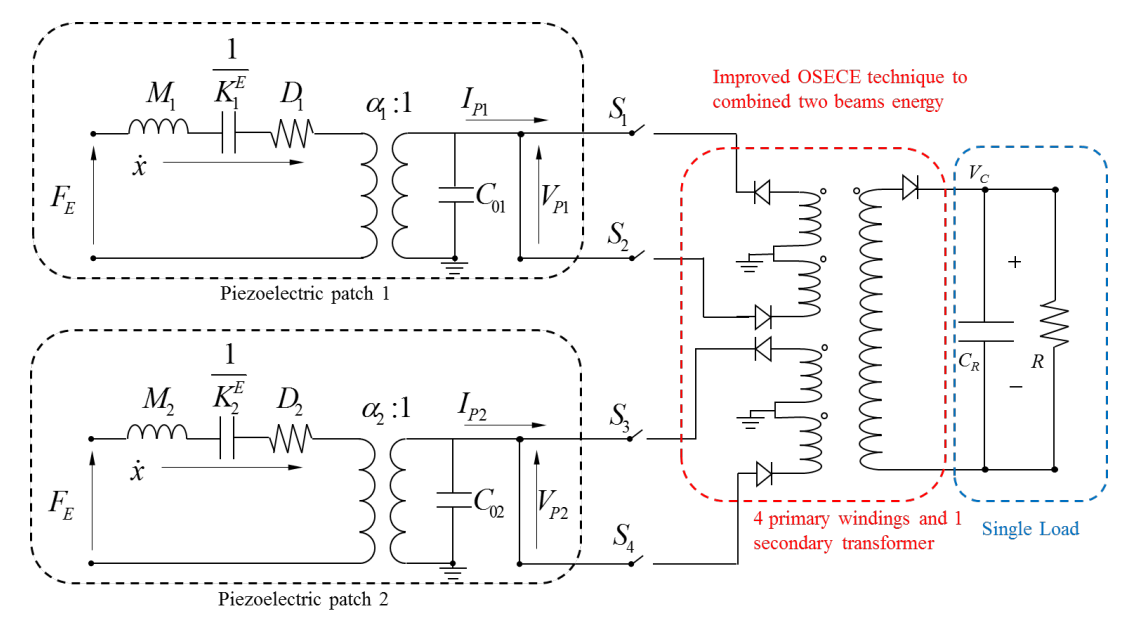

Figure 7. Equivalent circuit model of two piezoelectric patches charge to single load by improved OSECE technique.

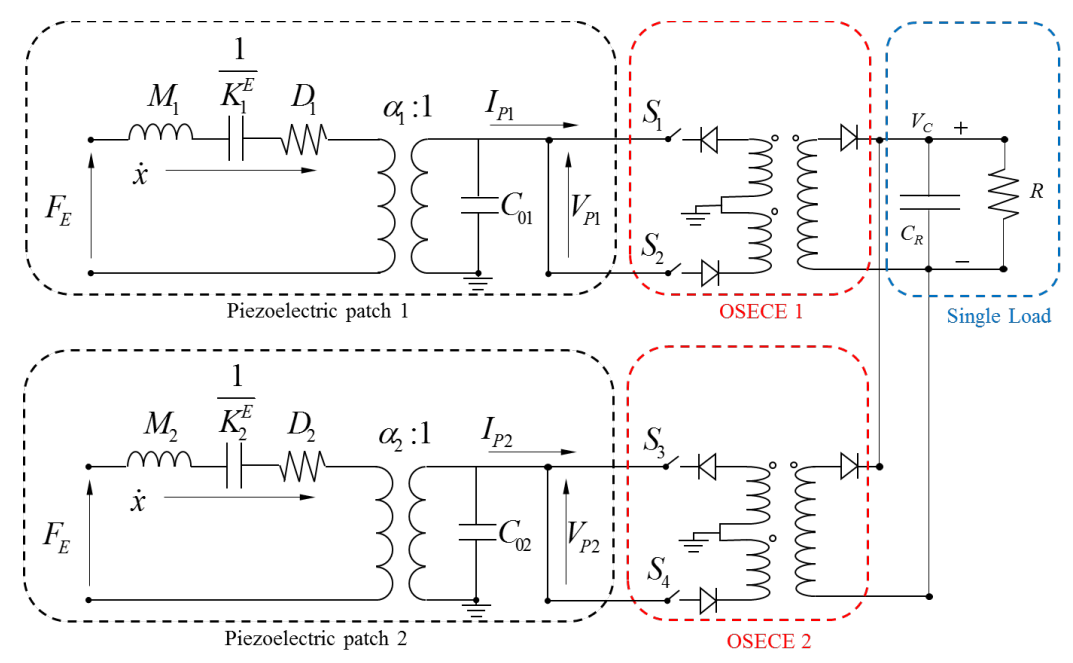

Figure 8. Simplified equivalent circuit model of two piezoelectric patches in experiment. 


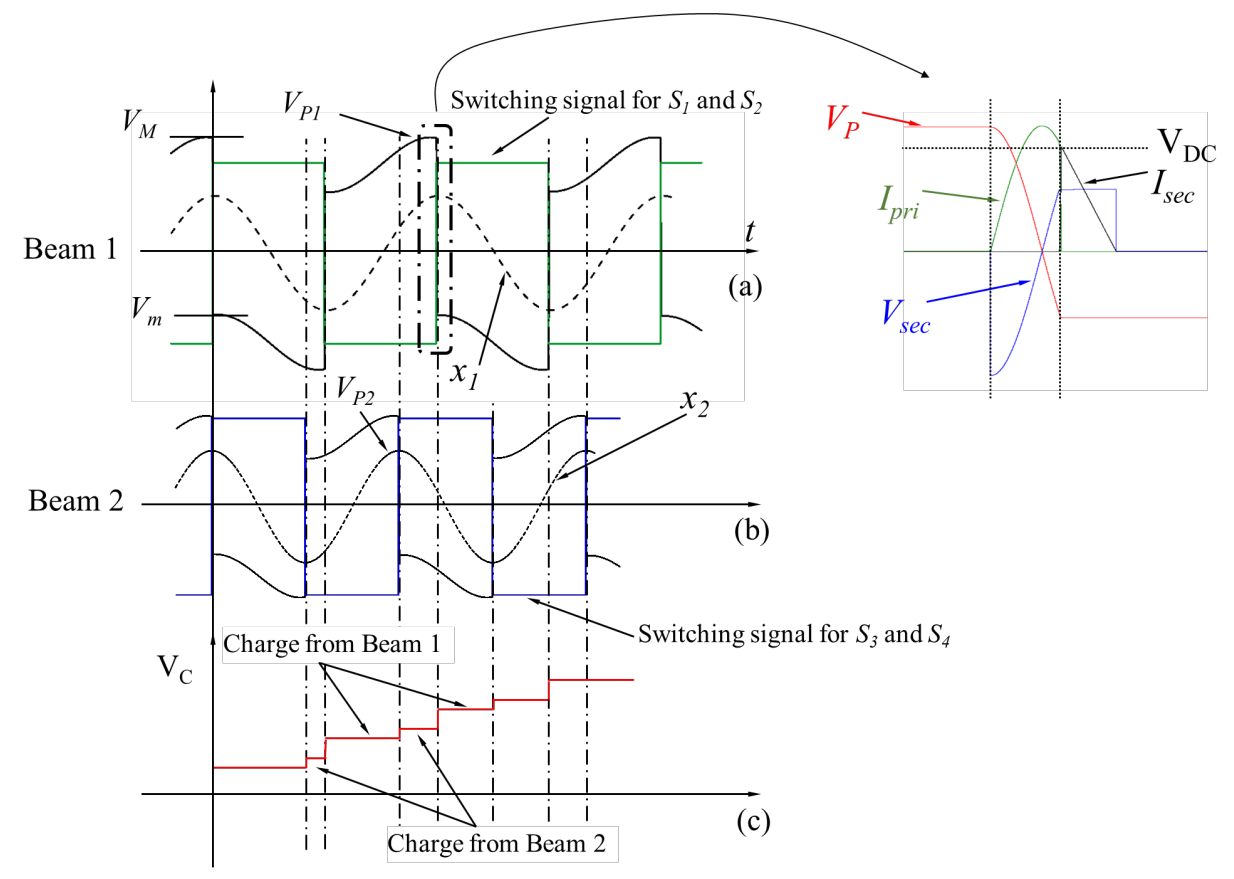

Figure 9. Waveform of the OSECE technique.

According to the equivalent circuit in Figure 8. The two beams combined energy harvesting system can be simulated by MATLAB + PSIM as shown in Figure 10. The simulation results can be plotted in 3-D and are shown in Figure 11. There are three simulations results: Beam 1, Beam 2 and Beam 1+ Beam 2. From the simulation results, the optimal load range is almost a flat curve between $10 \mathrm{k} \Omega$ to $500 \mathrm{k} \Omega$ in three cases. When the two cantilever beams are combined with the OSESE to charge a single load, the load curve will not be changed and the optimal load is the same as the singe beam. In the frequency response, the two beams combined system also shows good performance to plus the energy together.

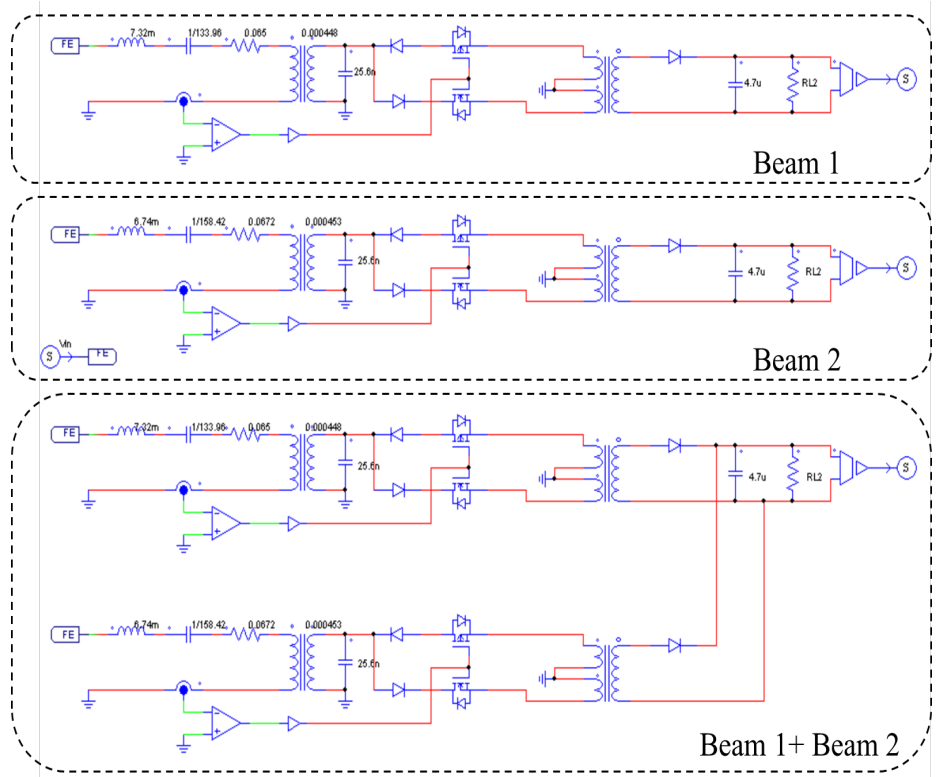

Figure 10. Simulation circuit diagram in PSIM. 


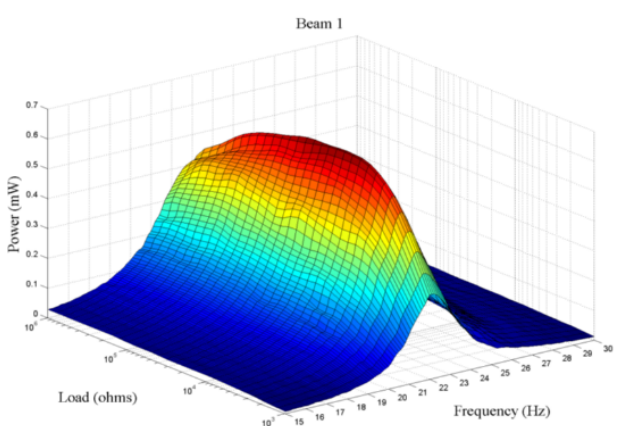

(a)

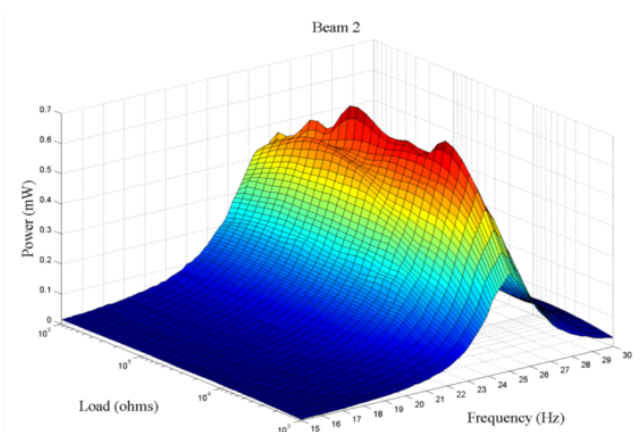

(b)

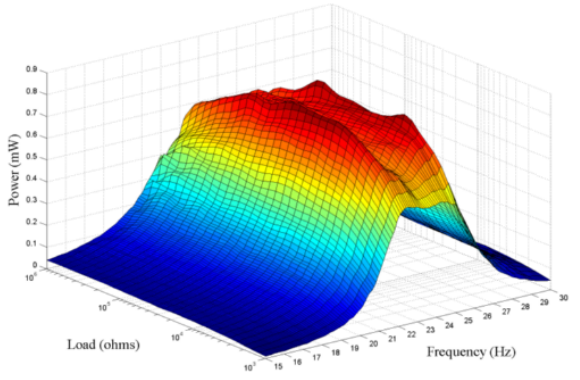

(c)

Figure 11. Simulation results of two beams piezoelectric energy harvester. (a)Cantilever beam 1 (b) Cantilever beam 2 (c) Cantilever beam $1+$ Cantilever beam 2

\section{EXPERIMENTAL RESULTS AND DISCUSSTION}

The experimental setup photos are shown in Figure 12. Two cantilever beams are placed on the vibrating shaker (LDS V406) by the mechanical clamper and the vibrating shaker are driven by the power amplifier (LDS PA100E). The driving signal is generated from the NI DAQ card (NI USB-6353) and LabVIEW software. An accelerometer (PCB 353B03, PIEZOTRONICS) is placed on the mechanical clamper to measure the acceleration and a Laser vibrometer (LK-G152 and LK-G3001P, KEYENCE) is place on the top of the cantilever beam to measure the tip displacement. Two cantilever beams are driven by the vibrating shaker together and through two combined OSECE interfacing circuit the harvested energy from two patches charge to a single load. Two diodes, one transformer and two switches are used in each OSECE interfacing circuit as Figure 8 shown. The model of diodes used here are BAT48 and the voltage drop is around $0.22 \mathrm{~V}$. The model of transformer is PT8SM. There are two windings in primary side and one winding in the secondary side. The turn's ratio is 1:1:2 and the inductance is around $10 \mathrm{mH}$. The output rectifier capacitor is $4.7 \mathrm{uF}$. The dimensions and model parameters of the two cantilever beams are shown in Table 1 and Table 2. Two resonant frequencies of two cantilever beams are designed to close to each other and it will be easier to show the results.
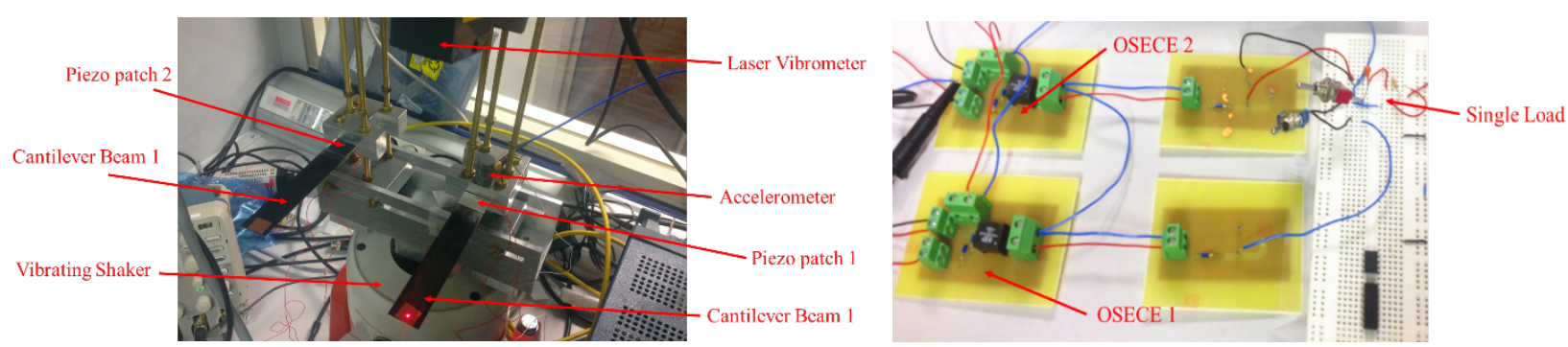
Figure 12. Photos of experimental setup and interfacing circuit.

Table 1. Dimensions and model parameters of the Cantilever beam 1

\begin{tabular}{|c|l|c|}
\hline Symbol & Description & Value (unit) \\
\hline Size of the spring steel beam & Length $\times$ Width $\times$ Thickness & $118 \times 20.5 \times 0.5\left(\mathrm{~m}^{3}\right)$ \\
\hline Size of piezoelectric patch & Length $\times$ Width $\times$ Thickness & $20 \times 14 \times 0.3\left(\mathrm{~m}^{3}\right)$ \\
\hline $\mathrm{f}_{\mathrm{op} 1}$ & Open circuit resonant frequency & $21.53 \mathrm{~Hz}$ \\
\hline $\mathrm{f}_{\mathrm{sh} 1}$ & Short circuit resonant frequency & $21.45 \mathrm{~Hz}$ \\
\hline $\mathrm{k}_{1}^{2}$ & Electromechanical coupling coefficient & 0.0074 \\
\hline$\zeta_{1}$ & Damping ratio & 0.0328 \\
\hline $\mathrm{Q}_{\mathrm{M} 1}$ & Mechanical quality factor & 30.5 \\
\hline $\mathrm{M}_{1}$ & Mass & $133.96 \mathrm{~g} / \mathrm{m}$ \\
\hline $\mathrm{K}^{\mathrm{D} 1}$ & $\begin{array}{l}\text { Equivalent stiffness when all piezoelectric element is } \\
\text { in open circuit }\end{array}$ & $132.96 \mathrm{~N} / \mathrm{m}$ \\
\hline $\mathrm{K}^{\mathrm{E} 1}$ & $\begin{array}{l}\text { Equivalent stiffness when all piezoelectric element is } \\
\text { in short circuit }\end{array}$ & $0.065 \mathrm{~N} / \mathrm{m} / \mathrm{s}$ \\
\hline $\mathrm{D}_{1}$ & Damping coefficient & $0.000448 \mathrm{~N} / \mathrm{V}$ \\
\hline$\alpha_{1}$ & Force-voltage factor & $25.6 \mathrm{nF}$ \\
\hline $\mathrm{C}_{01}$ & Clamped capacitance of \\
\hline
\end{tabular}

Table 2. Dimensions and model parameters of the Cantilever beam 2

\begin{tabular}{|c|l|c|}
\hline Symbol & Description & Value (unit) \\
\hline Size of the spring steel beam & Length $\times$ Width $\times$ Thickness & $110 \times 20 \times 0.5\left(\mathrm{~m}^{3}\right)$ \\
\hline Size of piezoelectric patch & Length $\times$ Width $\times$ Thickness & $20 \times 14 \times 0.3\left(\mathrm{~m}^{3}\right)$ \\
\hline $\mathrm{f}_{\mathrm{op} 2}$ & Open circuit resonant frequency & $24.4 \mathrm{~Hz}$ \\
\hline $\mathrm{f}_{\mathrm{sh} 2}$ & Short circuit resonant frequency & $24.29 \mathrm{~Hz}$ \\
\hline $\mathrm{k}_{2} \mathrm{~S}_{2}$ & Electromechanical coupling coefficient & 0.009 \\
\hline $\mathrm{Q}_{\mathrm{M} 2}$ & Damping ratio & 0.0312 \\
\hline $\mathrm{M}_{2}$ & Mechanical quality factor & 31.93 \\
\hline $\mathrm{K}^{\mathrm{D} 2}$ & Mass & $6.74 \mathrm{~g}$ \\
\hline $\mathrm{K}^{\mathrm{E} 2}$ & $\begin{array}{l}\text { Equivalent stiffness when all piezoelectric element is } \\
\text { in open circuit }\end{array}$ & $158.42 \mathrm{~N} / \mathrm{m}$ \\
\hline $\mathrm{D}_{2}$ & $\begin{array}{l}\text { Equivalent stiffness when all piezoelectric element is } \\
\text { in short circuit }\end{array}$ & $156.99 \mathrm{~N} / \mathrm{m}$ \\
\hline$\alpha_{2}$ & Damping coefficient & $0.0672 \mathrm{~N} / \mathrm{m} / \mathrm{s}$ \\
\hline $\mathrm{C}_{02}$ & Force-voltage factor & $0.000453 \mathrm{~N} / \mathrm{V}$ \\
\hline & Clamped capacitance of & $24.9 \mathrm{nF}$ \\
\hline
\end{tabular}

In order to verify the two beams energy harvesting system, there are two cases tested to show the results. In the following testing, the acceleration is $3.3 \mathrm{~m} / \mathrm{s}^{2}$.

Case 1: sweeping the cantilever beam 1, beam 2 and two beams combined with the resistor load and measure the output power. Two cantilever beams are driven at each resonant frequency $21.5 \mathrm{~Hz}$ and $24.4 \mathrm{~Hz}$ and the experimental results are shown in Figure 13(a) and (b). The blue dash-line is the result of beam 1, the green dash-line is the results of beam 2 and 
red line is the results of the two beams combined system. The optimal load for beam 1, beam 2 and two beams combined are almost the same and the optimal load is around $67 \mathrm{k} \Omega$. Here also shows that in the OSECE technique, the optimal load range is wider than classical synchronized switching technique harvesting in inductor (SSHI). The output power during the resistor load from $20 \mathrm{k} \Omega$ to $200 \mathrm{k} \Omega$ is almost a flat curve whatever beam 1, beam 2 or two beams. The results also shows that by using OSECE technique to combine two beams to a single load the optimal load will not be changed. This technique will not influence the load response curve. It means that whole system is load independent and this result shows good agreement with the simulations results in Figure 11.

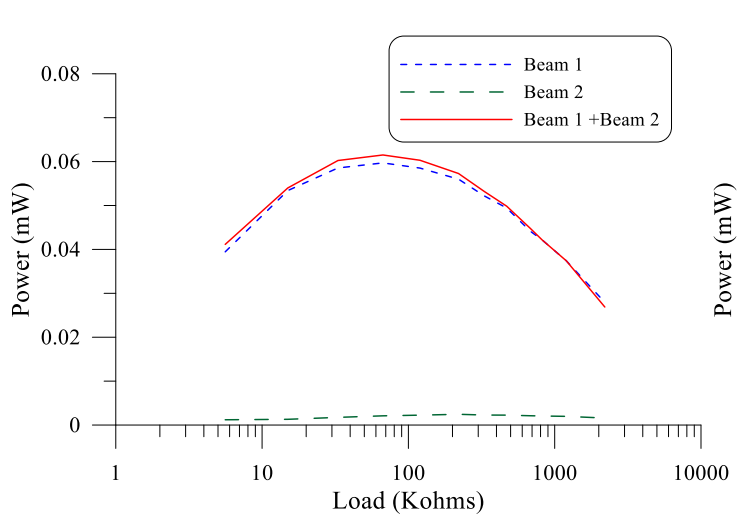

(a)

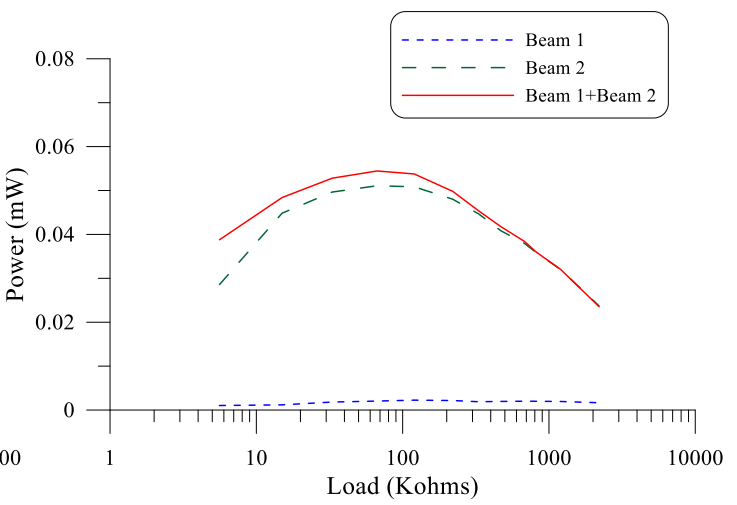

(b)

Figure 13. Load response results at (a) $21.5 \mathrm{~Hz}$ (b) $24.4 \mathrm{~Hz}$.

Case 2: sweeping the cantilever beam 1 , beam 2 and two beams combined with the frequency from $18 \mathrm{~Hz}$ to $28 \mathrm{~Hz}$ and measure the output power. Two cantilever beams are driven at the optimal load $(67 \mathrm{k} \Omega)$ and the experimental results are shown in Figure 14. The blue dash-line is the result of beam 1, the green dash-line is the results of beam 2 and red line is the results of the two beams combined system. The results clearly show that the two beams combined system can almost combine the two beams energy efficiently. When the driving frequency is close to the resonant frequency of beam 1 and beam 2, as the power output gap between two beams are too large the combined system cannot increase power output too much but also show good efficiency to charge a single load. When the driving frequency is between the resonant frequency of Beam 1 and Beam $2(21.5 \mathrm{~Hz}$ to $24.4 \mathrm{~Hz})$, the two beam combined system shows good performance to plus the energy from beam 1 and beam 2 efficiently. Comparing the two beams combined system curve to beam 1 and beam 2, the OSECE combined technique will not influence the frequency response of each cantilever beam and the output power of two beams are plus together to a single load. These results also show good agreement with the simulation results. 


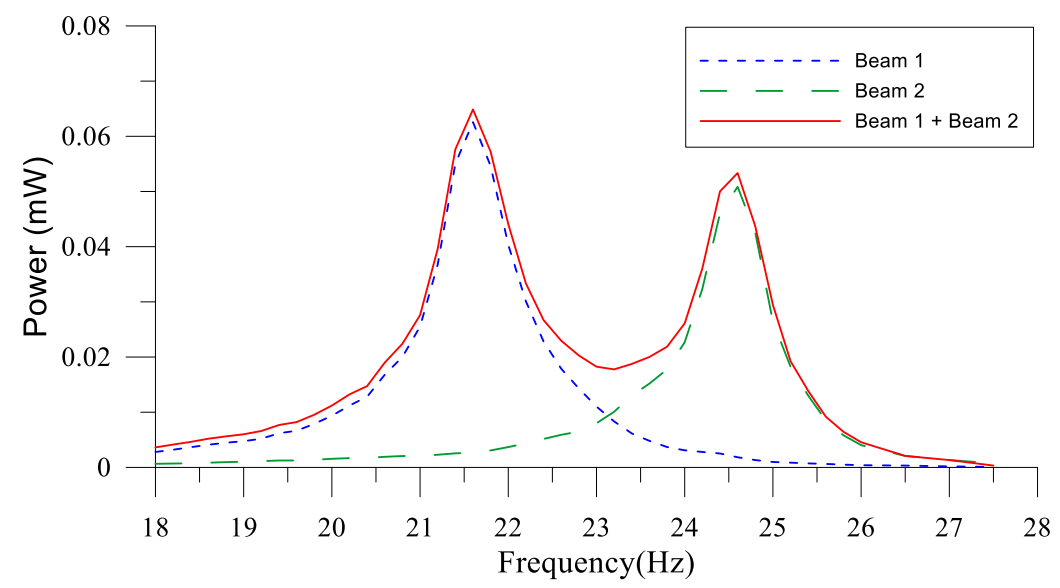

Figure 14. Experimental results of two beams combined energy harvester.

\section{CONLCUSION}

In this study, an electric interface (OSECE) is proposed to connect two piezoelectric beams with only one load. Experimental results verify the simulation results by MATLAB and PSIM software. In the load response testing (driven at each resonance), OSECE technique with two beams show low dependence on load effect. The wide optimal load range is an advantage in real application and for multi-piezoelectric system. The two beams combined system will not influence the load curve for each piezo patch. In the frequency response testing (at the optimal load), the two beams combined system show good performance to plus electrical energy from two beams and will not influence the frequency response for each piezo patch either. When the external driving frequency is between two resonant frequencies the two beams combined system have the best performance to plus the electrical energy from two beams.

The two beams system proposed in this study is the simplest system in the multi-piezoelectric patches system. The results show that the combined technique can be used in multi-piezoelectric patch system and plus the electrical energy without influencing the load curve and frequency response. This advantage is important to different piezoelectric patches and different structure design applications. As the piezoelectric flag energy harvesting application, the whole system can be composed of many piezoelectric patches and only load need to be charge

\section{ACKNOWLEDGMENT}

The funding of this project, from Agence Nationale de la Recherche, France under ANR FLUTTENER project, is gratefully acknowledged.

\section{REFERENCES}

[1] H. A. Sodano, et al., "A review of power harvesting from vibration using piezoelectric materials" vol. 36. Thousands Oaks, CA, USA: Sage, 2004.

[2] S. Roundy, "On the effectiveness of vibration-based energy harvesting," Journal of Intelligent Material Systems and Structures, vol. 16, pp. 809-823, Oct 2005.

[3] E. Lefeuvre, et al., "Piezoelectric energy harvesting device optimization by synchronous electric charge extraction," Journal of Intelligent Material Systems and Structures, vol. 16, pp. 865-876, Oct 2005.

[4] D. Guyomar, et al., "Toward energy harvesting using active materials and conversion improvement by nonlinear processing," IEEE Trans. Ultrason. Ferroelectr. Freq. Control, vol. 52, pp. 584-595, 2005.

[5] E. Lefeuvre, et al., "A comparison between several approaches of piezoelectric energy harvesting," Journal De Physique Iv, vol. 128, pp. 177-186, 2005. 
[6] M. Lallart, et al, "Double synchronized switch harvesting (DSSH): A new energy harvesting scheme for efficient energy extraction," IEEE Trans. Ultrason. Ferroelectr. Freq. Control, vol. 55, pp. 2119-2130, 2008.

[7] Y. Y. Chen, et al., "A self-powered switching circuit for piezoelectric energy harvesting with velocity control," European Physical Journal-Applied Physics, vol. 57, 3090, Feb 2012.

[8] T. H. Ng and W. H. Liao, "Sensitivity analysis and energy harvesting for a self-powered piezoelectric sensor," Journal of Intelligent Material Systems and Structures, vol. 16, pp. 785-797, Oct 2005.

[9] S. Kim, W. W. Clark, and Q.-M. Wang, "Piezoelectric Energy Harvesting with a Clamped Circular Plate: Analysis," Journal of Intelligent Material Systems and Structures, vol. 16, pp. 847-854, Oct 2005.

[10] M. Umeda, K. Nakamura, and S. Ueha, "Energy storage characteristics of a piezo-generator using impact induced vibration," Japanese Journal of Applied Physics Part 1-Regular Papers Short Notes \& Review Papers, vol. 36, pp. 3146-3151, 1997.

[11] G. K. Ottman, H. F. Hofmann, and G. A. Lesieutre, "Optimized piezoelectric energy harvesting circuit using step-down converter in discontinuous conduction mode," IEEE Trans. Power Electron, vol. 18, pp. 696-703, 2003.

[12] S. Roundy and P. K. Wright, "A piezoelectric vibration based generator for wireless electronics," Smart Materials \& Structures, vol. 13, pp. 1131-1142, Oct 2004.

[13]E. Lefeuvre, A. Badel, C. Richard, and D. Guyomar, "High performance piezoelectric vibration energy reclamation," Smart Structures and Materials 2004: Smart Structures and Integrated Systems, vol. 5390, pp. 379-387, 2004.

[14]Y. Wu, A. Badel, F. Formosa, et al., Piezoelectric vibration energy harvesting by optimized synchronous electric charge extraction. Journal of Intelligent Material Systems and Structures 24(12): 1445-1458, 2012.

[15]Y. C. Shu, I. C. Lien, and W. J. Wu, "An improved analysis of the SSHI interface in piezoelectric energy harvesting," Smart Materials \& Structures, vol. 16, pp. 2253-2264, Dec 2007.

[16] Y.Y. Chen, D. Vasic, F. Costa, C.K. Lee, W.J. Wu, Self-Powered Semi-Passive Piezoelectric Structural Damping Based on Zero Velocity Crossing Detection. Smart Materials \& Structures, Volume 22, Issue 2, 025029, February 2013

[17] Y.Y. Chen, D. Vasic, F. Costa, C.K. Lee, W.J. Wu, Self-Powered Semi-Passive Piezoelectric Structural Damping Based on Zero Velocity Crossing Detection. Smart Materials \& Structures, Volume 22, Issue 2, 025029, February 2013

[18] Y.Y. Chen, D. Vasic, Y.P. Liu, F. Costa, Study of a Piezoelectric Switching Circuits for Energy Harvesting with Bistable Broadband Technique by Work-cycle Analysis. Journal of Intelligent Materials Systems \& Structures, Volume 24, Issue 2, pp. 180-193, January 2013

[19] H. Wu, L. Tang, Y. Yang, and C.K. Soh, 2013, "A Novel Two-Degrees-of-Freedom Piezoelectric Energy Harvester,” J. Intell. Mater. Syst. Struct., 24(3), pp. 357-368.

[20] O. Doaré, and S. Michelin, "Piezoelectric coupling in energy-harvesting fluttering flexible plates: linear stability analysis and conversion efficiency." Journal of Fluids and Structures 27.8 (2011): 1357-1375.

[21] S. Michelin, and O. Doaré, "Energy harvesting efficiency of piezoelectric flags in axial flows." Journal of Fluid Mechanics 714 (2013): 489-504. 